\title{
Health systems research initiative to tackle growing road traffic injuries in India
}

\author{
Bontha V Babu*, Yogita Sharma \\ Indian Council of Medical Research, New Delhi, India
}

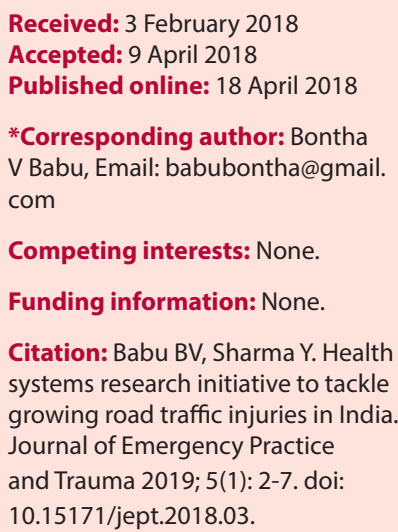

\begin{abstract}
Road traffic injuries (RTIs) are the sixth leading cause of deaths in India and about 400 deaths take place every day due to road traffic accidents. The present paper analyses the data of the India's National Crime Record Bureau (NCRB) to assess the burden of RTI. In addition, it reports the health systems research initiated by the Indian Council of Medical Research (ICMR). As per NCRB data, in 2015, 6.3 million persons (50 persons per 10 million population) injured and out of them 1.4 million (11 persons per 10 million population) died in India. Except the NCRB data, there are no nation-wide data on RTI and the data remain poorly collected and sporadic in India. Hence, ICMR has initiated a multi-centric study to establish an electronic-based comprehensive and integrated RTI surveillance system. The second issue on which ICMR undertake research is timely and quality care of RTI patients as many deaths occur either at the scene or en route to the hospital. There is a clear survival and functional benefit for critically injured patients to receive appropriate care within the first 60 minutes of injury ('golden hour'). Hence, this multicentric study has been initiated to standardize structured evidence-based intervention for safety, efficacy and quality of post-crash pre-hospital and in-hospital trauma care services to improve the outcome in RTI victims. An android-based trauma registry is being built and will be used to assess the impact of interventions. These studies will provide first comprehensive estimates on various epidemiological issues related to RTI. Also, an evidence of improvement through quality post-crash prehospital and in-hospital trauma care services will emerge. These results will contribute to the setting of research and investment priorities and to formulate policies and guidelines.

Keywords: Road traffic injuries, Road traffic accidents, Trauma, Surveillance, Registry, Intervention, India
\end{abstract}

\section{Introduction}

The World Health Organization (WHO) estimates that over 1.2 million people die each year on the world's roads and between 20 and 50 million fall victim to non-fatal injuries (1). About $90 \%$ of global injury-related deaths occur in low and middle income countries like India (2). India with a population of 1.3 billion, is one of the growing economies. Road traffic injuries (RTIs) are the sixth leading cause of deaths in India and about 400 deaths take place every day due to RTA (3). In addition to riders of vehicles, most of the time, pillions, pedestrians, bicyclists and walkers are killed and disabled in large numbers (4). India is a federal republic under parliamentary system consisting of 29 states and 7 union territories, which vary remarkably in development and economy. The present paper analyses the data of the India's National Crime Record Bureau (NCRB) to assess the burden of RTI in terms of number of injuries and deaths. In addition, it reports the health systems research initiated by the Indian Council of Medical Research (ICMR) towards developing evidences and plans for implementation research needs to tackle the growing burden of RTI. Data of the present study were taken from the public domain of the NCRB. The NCRB, an organization under the government of India, functions as a clearinghouse for information related to crimes and unnatural deaths, injuries occurring in the country. Through Crime and Criminal Information System (CCIS), NCRB developed a national network, connecting the police headquarters at 727 police districts and 36 states/union territories, and the central data repository at the NCRB in New Delhi. It uses standard input integrated investigation forms and the data are obtained from police stations in the district. Records fed in at the district level are periodically updated at the center through the offline/ online system of data transfer. Thus, this network amassed data from 15 thousand police stations through district and state/union territory levels for national figures at national level at the central data repository at the NCRB, New Delhi (5). 


\section{Burden of RTI}

As per NCRB data, in 2015, 631 thousand persons injured and out of them 149 thousand died (Table 1). This indicates that 48.9 persons per 100 thousand population in India were injured and 11.5 persons per 100 thousand population died in 2015. Developed countries have reported very low fatality rates than India like 2.8 (the United Kingdom), 4.2 (Germany), 5.3 (France), 5.6 per 100 thousand population (Austria), etc (6). It is noted from the NCRB data that a remarkable interstate variations exist in both injury rates and death rates (Table 1). The variations in injury rates are due to several reasons like conditions of roads and vehicles, and implementation of safety measures. However, the fatality rate amongst road traffic accident (RTA) victims is different and it depends on health system's response. Unfortunately, 50\%-60\% of deaths occur either at the scene or en route to the hospital (7). These fatality rates (percentage of deaths out of total RTA victims) varied remarkably across Indian states and union territories (Figure 1). On average, 23.6\% of RTA victims died in 2015. This rate is as high as $52.6 \%$ in Punjab. Interestingly, this rate is very low in some states, for example, the death rate in Kerala is $8.8 \%$. It is necessary to look critically into this inter-state variation to understand

Table 1. State wise details of road traffic injuries (RTIs) and death in the year 2015

\begin{tabular}{|c|c|c|c|c|c|}
\hline State/Union territory & $\begin{array}{l}\text { Total victims in } \\
\text { accidents }\end{array}$ & $\begin{array}{l}\text { Total accident } \\
\text { deaths }\end{array}$ & $\begin{array}{l}\text { Projected population in } 2015 \\
\text { (in thousands)* }\end{array}$ & $\begin{array}{l}\text { RTI rate (per } 100 \\
\text { thousand) }\end{array}$ & $\begin{array}{l}\text { RTI death rate (per } \\
100 \text { thousand) }\end{array}$ \\
\hline Andhra Pradesh & 37736 & 8297 & 87662 & 43.05 & 9.46 \\
\hline Arunachal Pradesh & 560 & 177 & 1299 & 43.11 & 13.63 \\
\hline Assam & 9452 & 2384 & 32069 & 29.47 & 7.43 \\
\hline Bihar & 11825 & 5500 & 102732 & 11.51 & 5.35 \\
\hline Chhattisgarh & 17508 & 4082 & 25555 & 68.51 & 15.97 \\
\hline Goa & 2568 & 314 & 1953 & 131.49 & 16.08 \\
\hline Gujarat & 29750 & 8245 & 62081 & 47.92 & 13.28 \\
\hline Haryana & 15664 & 5045 & 27079 & 57.85 & 18.63 \\
\hline Himachal Pradesh & 6204 & 1096 & 7037 & 88.16 & 15.57 \\
\hline Jammu \& Kashmir & 9171 & 923 & 12289 & 74.63 & 7.51 \\
\hline Jharkhand & 6931 & 2893 & 33203 & 20.87 & 8.71 \\
\hline Karnataka & 67828 & 10857 & 61797 & 109.76 & 17.57 \\
\hline Kerala & 47664 & 4196 & 35473 & 134.37 & 11.83 \\
\hline Madhya Pradesh & 50636 & 9758 & 76745 & 65.98 & 12.71 \\
\hline Maharashtra & 52986 & 13685 & 118652 & 44.66 & 11.53 \\
\hline Manipur & 1247 & 129 & 2563 & 48.65 & 5.03 \\
\hline Meghalaya & 794 & 205 & 2743 & 28.95 & 7.47 \\
\hline Mizoram & 143 & 65 & 1051 & 13.61 & 6.18 \\
\hline Nagaland & 103 & 47 & 2354 & 4.38 & 2.00 \\
\hline Odisha & 16128 & 4303 & 42138 & 38.27 & 10.21 \\
\hline Punjab & 9307 & 4893 & 28846 & 32.26 & 16.96 \\
\hline Rajasthan & 36663 & 10510 & 71973 & 50.94 & 14.60 \\
\hline Sikkim & 396 & 75 & 640 & 61.88 & 11.72 \\
\hline Tamil Nadu & 95388 & 15642 & 69030 & 138.18 & 22.66 \\
\hline Telangana & 30058 & 7110 & 37700 & 79.73 & 18.86 \\
\hline Tripura & 1187 & 158 & 3784 & 31.37 & 4.18 \\
\hline Uttar Pradesh & 35791 & 18407 & 214671 & 16.67 & 8.57 \\
\hline Uttarakhand & 2570 & 913 & 10499 & 24.48 & 8.70 \\
\hline West Bengal & 22109 & 6705 & 92725 & 23.84 & 7.23 \\
\hline Andaman \& Nicobar Islands & 354 & 23 & 543 & 65.19 & 4.24 \\
\hline Chandigarh & 460 & 129 & 1719 & 26.76 & 7.50 \\
\hline Dadra and Nagar Haveli & 139 & 42 & 414 & 33.57 & 10.14 \\
\hline Daman and Diu & 106 & 42 & 317 & 33.44 & 13.25 \\
\hline Delhi & 9880 & 1622 & 20676 & 47.78 & 7.84 \\
\hline Lakshadweep & 3 & 0 & 79 & 3.80 & 0.00 \\
\hline Puducherry & 1787 & 235 & 1626 & 109.90 & 14.45 \\
\hline India & 631096 & 148707 & 1291717 & 48.86 & 11.51 \\
\hline
\end{tabular}

Source: NCRB, 2017 (5); *Census of India, 2011 (24). 


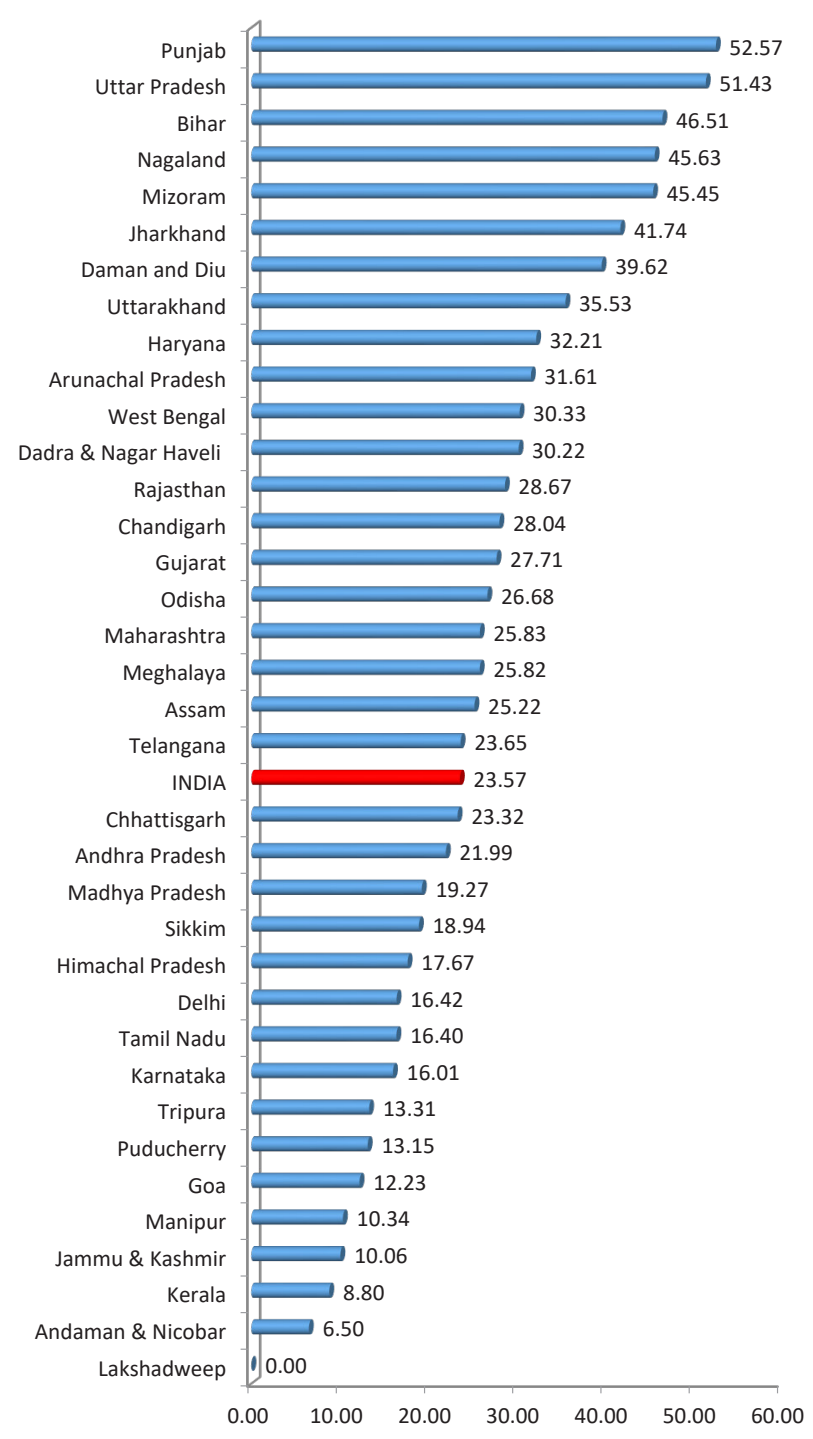

Figure 1. State-wise fatality rate among total road traffic accident victims in India in the year 2015.

the factors influencing the survival of the RTA victims. In addition, the reporting of accidents and consequent deaths and hospitalization by police is too important. As mentioned earlier, this rate remarkably depends on the health system's responsiveness and efficient post-crash care, particularly by prompt and quality trauma care. Data from European Union, where the health system is more responsive, the fatality rate among the RTA victims vary from 0.8 (in United Kingdom and Malta) to 7.9\% (in Bulgaria), with an average of 1.8 for all EU countries (6).

\section{Research initiatives of ICMR \\ Establishment of RTI surveillance}

It is to be noted that except the NCRB data, there are no nation-wide data on RTI. The data on RTI remain poorly collected and sporadic in India, despite the burden is huge. Weak or no estimates of morbidity due to RTA is a common problem in low and middle-income countries, where data sources are often of poor quality, non- representative, difficult to access and contain a limited number of relevant variables (8). Hence, surveillance of RTI is recommended to assess the burden, identify high-risk groups, establish association with probable risk factors and plan interventions to control the occurrence and monitor the impact (9). Effective RTI surveillance systems set up in developing countries have shown promising results in controlling the problem (10). Hence, ICMR has initiated a study to establish an electronicbased comprehensive and integrated RTI surveillance system. After establishing the system and demonstrating the feasibility of establishment within the public health system, it can be taken over by the government for scaledup. It is the responsibility of the health sector to ensure the establishment of necessary data systems, which will be enabled thorough collection of information related to RTI (11).

Since RTAs are more common on urban roads and on roads connected to urban area and it has been seen that majority of the cases are referred to tertiary care hospitals, hence a passive surveillance system in tertiary care hospitals is being established. It is possible that most of the critical and immediately fatal cases are recorded and those who die in government hospitals also enter the official statistics through police network. As more than $60 \%$ of the fatalities occur in rural areas (12), it is possible that a larger number of cases go unreported on rural roads, particularly non-fatal and minor injuries. Also, a significant proportion of fatalities that occur many days after the crash in rural areas are missed. Even some deaths escape from police records as parties involved in the accidents settle the dispute out of the legal system. In addition to all these, many non-fatal and minor injuries were treated in smaller nursing homes and clinics. Usually these facilities are of private in nature, and they do not like to involve in medico-legal cases. Many times, the parties also do not like to register the case with police and they prefer to settle the issue out of the legal system. In view of these realities, the present study is being developed and integrated an active surveillance system to cover police stations, community-based health facilities like primary health centers, community health centers, private nursing homes and clinics. Active surveillance is also being placed in communities to track missing cases. Necessary mechanism is integrated in the software system to avoid duplications. Thus, the present study will establish both passive and active surveillances comprehensively to capture all RTIs and related deaths in a particular geographical area. This study is being implemented in five places in India, viz. Chennai, Chittoor, Dehradun, Delhi and Jaipur.

\section{Standardizing quality trauma care}

The second issue on which ICMR is keen to undertake research is timely and quality care of RTI patients as 50\%- 
$60 \%$ of deaths occur either at the scene or en route to the hospital (7). Timely and adequate care of trauma patient is of utmost importance and can drastically improve the chance of survival. There is a clear survival and functional benefit for critically injured patients to receive appropriate care within the first 60 minutes after injury. This concept is called the 'golden hour' (13). Faster response time and adequate prehospital care during this period can dramatically improve these outcomes in critically injured patients (14). Based on the existing reports, majority of the RTI deaths is due to unreachability for basic and integrated emergency services, which lead to failure in utilizing golden hour for saving either life or major disability. Hence, this study has been initiated with the objective to standardize structured evidence-based intervention for safety, efficacy and quality of post-crash pre-hospital and in-hospital trauma care services to improve the outcome in RTI victims.

Improving and establishing prehospital care is one of the objectives of this study. The intervention on prehospital care includes education and training for prehospital care and prehospital notification, standardized hospital selection, mandatory checklist for persons attending RTI and prior notification of arrival. Trauma resuscitation management of immediately life-threatening injuries requires rapid identification and management of threats to airway and breathing, bleeding, cardiac and brain function. With sufficient notice, trauma hospitals can usually mobilize a team with relevant expertise to be present and ready for patient arrival. Pre-hospital notification alone has been found to be associated with reduced mortality and improved outcome (15).

Another interventional activity in this study is to educate and train the first-responders for above prehospital notification. The training will include (i) American Heart Association's basic life support training and certification including proper techniques of assessing and securing the scene safety, initial patient evaluation, proper cardio-pulmonary resuscitation (CPR) techniques and its indications, etc.; (ii) basic education on the initial assessment of a trauma patient; (iii) compliance with the basic necessities of any trauma patient including assessing and securing an airway, controlling an obvious hemorrhage, cervical-spine immobilization, ensuring strict spine precautions, establishing sufficient intravenous access, temporarily splinting a fracture dislocation, assessing the need for supplemental oxygen and obtaining at least one set of vitals every 5 minutes while en-route to the hospital; and (iv) standardization of hospital selection.

Intervention will be made to ensure the availability of ambulances to transport the critically injured patients according to strict prior set criteria. The list of all the qualifying hospitals per type of injury or injured patient will be available to the first-responders and posted in all the ambulances. The list of standardized hospitals shall be made in consultation during preparatory stage. There will be certain tasks/checklist that every personnel will be asked to perform on every patient they attend to for RTI. The checklist will include the followings: assess and clear the airway, assess and aid breathing, assess blood oxygenation and need for supplemental oxygen, assess pulse and peripheral circulation, begin CPR at any point in transit if no pulse, c-spine immobilization for appropriate injuries (high speed accidents, fall, blunt trauma to the neck or back, potential flexion-extension injury to the neck, hanging or near hanging, facial trauma, head trauma, etc.), keep strict spine precautions until cleared by a medical staff, obtain adequate intravenous access (two 18 gauge intravenous in the antecubital fossa) en route to the hospital, initiate intravenous fluid resuscitation if patient is hemodynamically unstable (systolic blood pressure $<90$ or heart rate $>100$ ), start supplemental oxygen, stabilize fractures and apply splints in appropriate situations (obvious fracture dislocations of extremities), apply tourniquets proximal to actively bleeding extremities (pulsatile bleed or continuous oozing) and obtain a set of vitals every 5-7 minutes.

As mentioned earlier, the recipient hospital will be notified about patient's basic injuries and vitals while enroute so that the receiving hospital has enough time to assemble a team which is ready to receive and treat the patient immediately upon arrival. This will minimize the delay in definitive care that the patient requires and optimally utilizes the golden hour. The effectiveness on the prehospital care will be assessed using the data collected through trauma registry. An android-based trauma registry is being built in all study sites. A detailed data set would be prepared to enter prehospital, in-hospital and discharge details of all the admitted patients. Registry is being established in the emergency department for 24/7 in the prescribed registry format.

The study is further aimed to strengthen the quality of care within the hospital. It will be achieved by supporting participating hospitals to develop locally relevant quality improvement (QI) activities according to WHO guidelines (1). These activities include WHO's trauma QI training for key clinicians followed by mentoring of developing the necessary structures and processes to conduct regular morbidity and mortality meetings, preventable death reviews, audit filters, risk adjusted benchmarking of key performance indicators where relevant and loop closures. A systematic review of impact of these QI activities has shown the improvement in process of care and patient outcome (1). There is evidence that establishment of an organized trauma system leads to improvement in patient outcome even in rural areas (16). A formal training in trauma care in the rural hospitals led to decreased length of time to transfer to appropriate hospitals as well as improved overall outcomes. This study further demonstrated the cost-effectiveness and financial feasibility of such implementation in rural settings (17). As mentioned earlier, the impact of the QI will be assessed 
through various outcome indicators including death, morbidity and length of hospital stay, collected through trauma registry.

\section{Conclusion}

RTIs have been recognized globally as an important public health problem, as they account for $15-50 \%$ of all injuries in India (18-20). Due to the growth of motorization and rapid expansion of road networks, there has been an increase in RTIs over the recent years. Road deaths and injuries are preventable. Many deaths and impact of injuries can be prevented with first aid if causalities are treated immediately and by taking victims at the earliest to appropriate trauma care center. 'Golden Hour' - the first hour after trauma, is vital from heath systems research perspective. Currently in India, the emergency medical services (EMS) are fragmented and a few states have recently implemented a version of EMS that responds to a toll-free call for the medical emergencies (21). The concepts of 'pre-hospital care' and 'golden hour' are still nonexistent especially in the rural, remote and resource poor regions (22). The situation needs serious efforts through governmental policies, including an improvement in the capacity of health systems. Decade of Action on Road Safety by 2020 of WHO South Asia Region targeted to continue strengthening qualified pre-hospital emergency medical services, basic and professional acute trauma care services in national and local settings, and to develop hospital trauma care system (23). These studies will provide first comprehensive estimates of outcomes in terms of epidemiology and outcome of various degrees of RTI. The results of these studies will contribute to the setting of research and investment priorities to tackle the burden of RTIs. Also, an evidence of improvement through quality post-crash prehospital and in-hospital trauma care services will emerge from the second study. This evidence is required for formulating policies and guidelines.

\section{Ethical issues}

Not required.

\section{Authors' contributions}

BVB conceived the study; YS compiled and analysed the data; BVB and YS drafted the manuscript; BVB critically revised the manuscript for intellectual content; BVB and YS read and approved the final manuscript.

\section{Acknowledgements}

Authors acknowledge the support of Dr. Soumya Swaminathan, Director-General, Indian Council of Medical Research during developing and initiating the above mentioned multi-centric task force projects.

\section{References}

1. World Health Organization. Guidelines for trauma quality improvement programmes. Geneva, Switzerland: World
Health Organization; 2009.

2. World Health organization. Injuries and violence. The facts. Department of Violence and Injury Prevention and Disability. World Health Organization; 2010. [cited 20 Feb 2017]. Available from: http://apps.who.int/iris/ bitstream/10665/44288/1/9789241599375_eng.pdf.

3. Government of India. Integrated Disease Surveillance Project: Project Implementation Plan 2004-09. New Delhi: Ministry of Health and Family Welfare, Government of India; 2004. p. 1-18.

4. Gururaj G. Road deaths and injuries in India: Action required on the five pillars of road safety. Journal of Local and Global Health Science 2015; 2: 81-89. doi: 10.5339/ jlghs.2015.itma.81.

5. National Crime Records Bureau. Accidental Deaths \& Suicides in India - 2015. New Delhi: National Crime Records Bureau, Ministry of Home Affairs, Government of India; 2017. [cited 30 Jan 2017]. Available from: http://ncrb. nic.in/StatPublications/ADSI/ADSI2015/ADSI2015.asp.

6. European Commission. CARE-EU road accidents database or national publications. European Commission/ Directorate General Energy and Transport. [cited 2017 March 5]. Available from: https://ec.europa.eu/transport/ road_safety/sites/roadsafety/files/pdf/observatory/ historical_evol_popul.pdf.

7. Grossman DC, Kim A, Macdonald SC, Klein P, Copass MK, Maier RV. Urban-rural differences in prehospital care of major trauma. J Trauma 1997; 42(4): 723-9.

8. Bhalla K, Shahraz S, Bartels D, Abraham J. Methods for developing country level estimates of the incidence of deaths and non-fatal injuries from road traffic crashes. Int J Inj Contr Saf Promot 2009; 16(4): 239-48. doi: $10.1080 / 17457300903402184$.

9. Holder Y, Peden M, Krug EG, Lund J, Gururaj G, Kobusingye O. Injury Surveillance Guidelines. Geneva: WHO; 2001.

10. Razzak JA, Shamim MS, Mehmood A, Hussain SA, Ali MS, Jooma R. A successful model of Road Traffic Injury surveillance in a developing country: process and lessons learnt. BMC Public Health 2012; 12: 357. doi: 10.1186/14712458-12-357.

11. World Health Organization. World report on Road Traffic Injury Prevention. Geneva: World Health Organization; 2004.

12. Singh D, Singh SP, Kumaran M, Goel S. Epidemiology of road traffic accident deaths in children in Chandigarh zone of North West India. Egypt J Forensic Sci 2016; 6(3): 25560. doi: 10.1016/j.ejfs.2015.01.008.

13. Dinh MM, Bein K, Roncal S, Byrne CM, Petchell J, Brennan J. Redefining the golden hour for severe head injury in an urban setting: the effect of prehospital arrival times on patient outcomes. Injury 2013; 44(5): 606-10. doi: 10.1016/j. injury.2012.01.011.

14. Pons PT, Haukoos JS, Bludworth W, Cribley T, Pons KA, Markovchick VJ. Paramedic response time: does it affect patient survival? Acad Emerg Med 2005; 12(7): 594-600. doi: 10.1197/j.aem.2005.02.013.

15. Henry JA, Reingold AL. Prehospital trauma systems reduce mortality in developing countries: a systematic review and meta-analysis. J Trauma Acute Care Surg 2012; 73(1): 2618. doi: 10.1097/TA.0b013e31824bde1e. 
16. Husum H, Gilbert M, Wisborg T, Van Heng Y, Murad M. Rural prehospital trauma systems improve trauma outcome in low-income countries: a prospective study from North Iraq and Cambodia. J Trauma 2003; 54(6): 1188-96. doi: 10.1097/01.ta.0000073609.12530.19.

17. Dennis BM, Vella MA, Gunter OL, Smith MD, Wilson CS, Patel MB, et al. Rural Trauma Team Development Course decreases time to transfer for trauma patients. J Trauma Acute Care Surg 2016; 81(4): 632-7. doi: 10.1097/ ta.0000000000001188.

18. Jagnoor J, Suraweera W, Keay L, Ivers RQ, Thakur J, Jha P. Unintentional injury mortality in India, 2005: nationally representative mortality survey of 1.1 million homes. BMC Public Health 2012; 12: 487. doi: 10.1186/1471-2458-12487.

19. Alam K, Mahal A. The Economic Burden of Road Traffic Injuries on Households in South Asia. PLoS One 2016; 11(10): e0164362. doi: 10.1371/journal.pone.0164362.

20. Gururaj G, Uthkarsh PS, Rao GN, Jayaram AN,
Panduranganath V. Burden, pattern and outcomes of road traffic injuries in a rural district of India. Int J Inj Contr Saf Promot 2016; 23(1): 64-71. doi: $10.1080 / 17457300.2014 .945465$.

21. Sharma M, Brandler ES. Emergency medical services in India: the present and future. Prehosp Disaster Med 2014; 29(3): 307-10. doi: 10.1017/s1049023x14000296.

22. Nielsen K, Mock C, Joshipura M, Rubiano AM, Zakariah A, Rivara F. Assessment of the status of prehospital care in 13 low- and middle-income countries. Prehosp Emerg Care 2012; 16(3): 381-9. doi: 10.3109/10903127.2012.664245.

23. World Health Organization. Regional Report on Status of Road Safety: the South East Asia Region. A Call for Policy Direction. Regional Office of South East Asia, New Delhi: World Health Organization; 2009.

24. Census of India. Provisional Population Totals. New Delhi: Office of the Registrar General and Census Commissioner, Government of India, India; 2011. 